\title{
Is Sport Sponsorship Global? Evidence from the United States, the United Kingdom, and India
}

\author{
Noni Zaharia ${ }^{1}$, Kurt C. Mayer Jr. ${ }^{2}$, Eric Hungenberg ${ }^{3}$, Dianna Gray ${ }^{4}$ \& David Stotlar ${ }^{4}$ \\ ${ }^{1}$ Saint Joseph's University, Philadelphia, PA, U.S.A \\ ${ }^{2}$ Roanoke College, Salem, VA, U.S.A \\ ${ }^{3}$ The University of Tennessee at Chattanooga, TN, U.S.A \\ ${ }^{4}$ University of Northern Colorado, Greeley, CO, U.S.A \\ Corresponding author: Noni Zaharia, Department of Marketing, Erivan K. Haub School of Business, Saint \\ Joseph's University, 5600 City Avenue, Philadelphia, PA 19131, United States. E-mail: \\ noni_zaharia@yahoo.com
}

Received: March 4, 2016 Accepted: April 2, $2016 \quad$ Online Published: May 24, 2016

doi:10.5539/ijms.v8n3p43 URL: http://dx.doi.org/10.5539/ijms.v8n3p43

\begin{abstract}
This study sought to develop and test a cross-national sport sponsorship model. Sponsorship and Hofstede's cultural dimensions theories were utilized for the theoretical framework for this study. A survey was conducted with 522 Chelsea FC soccer club's fans from the United States, the United Kingdom, and India in the area of sponsorship through a jersey sponsorship. Single and multiple-group confirmatory factor analysis and structural equation modeling were used to analyze the global sport sponsorship model. The results acknowledged the measurement and structural invariance of a global model for five sport sponsorship outcomes (i.e., sponsorship awareness, sponsorship fit, attitude toward the sponsor, gratitude, and purchase intentions), controlling for age, gender, education, household income and the household's decision maker. The statistical analyses indicated that structural relationships among the analyzed sponsorship outcomes were invariant among all three countries. The effect of sponsorship fit predicted the presence of purchase intentions, while the attitude toward the sponsor was the strongest predictor of purchase intentions.
\end{abstract}

Keywords: global purchase intentions, global sponsorship, India, United Kingdom, United States

\section{Introduction}

In the current global economy, due to the development of new media technologies (e.g., broadband and mobile platforms), the distance across international markets is not the barrier it once was, and most companies are considered global brands within this universal marketplace (Amis \& Cornwell, 2005). However, a major impediment to global trading is the complexity of language and culture, which can be partially overcome through global sponsorship (Bartlett \& Ghoshal, 1989), that is the investment in an individual, event, team, or organization with the expectation of achieving certain corporate objectives in multiple countries (Amis \& Cornwell, 2005). Thus, global sport sponsorship could help surmount the challenges related with cultural and linguistic obstacles in a global society (Santomier, 2008). As such, outcomes of global sport sponsorship are important to international enterprises, as global and local objectives can be merged in sport sponsorship to present a reliable brand image across international markets (Rines, 2002). Adding to the importance of this area is that sponsorship employed across countries has been shown to be one of the most cost-effective strategies in sponsoring sport (Söderman \& Dolles, 2013). It is interesting then, that academic consideration dedicated to developing a better understanding of sport sponsorship, as part of international marketing, has yet to be conducted (Amis \& Cornwell, 2005; Santomier, 2008).

A variety of sport sponsorship outcomes, including awareness, fit, attitude toward the sponsor, gratitude, and purchase intentions have been examined in scholarly works (e.g., Alexandris, Tsiotsou, \& James, 2012; Biscaia, Correia, Rosado, Ross, \& Maroco, 2013; Kim, Smith, \& James, 2010). Despite the increasing number of studies measuring the above outcomes in different sport settings (e.g., Alexandris et al., 2012; Biscaia et al., 2013), a major gap exists in the understanding of how sponsorship outcomes function at a global level (Amis \& Cornwell, 2005; Santomier, 2008). Jersey sponsorship, ubiquitous in Europe and Asia, is a growing global revenue source 
in sports, and this sponsorship avenue gives companies an attractive media platform to reach their target customers (Biscaia, Correia, Ross, \& Rosado, 2014). However, it appears no sponsorship studies have empirically analyzed the effectiveness of jersey sponsorship at a cross-national stage.

Research also suggested that demographic information, such as annual household income, age, the household's decision maker, marital status, education, and race can predict purchase intentions (Sun \& Morwitz, 2010). For example, respondents that are more educated can provide more accurate responses regarding purchase intentions (Sun \& Morwitz, 2010). Moreover, considering national differences, in masculine cultures (i.e., the United States, the United Kingdom, and India) the decisions on larger purchases are usually made by males (Foscht, Maloles, Swoboda, Morschett, \& Sinha, 2008), and, as a result, they can sustain higher purchase intentions across countries than females. Therefore, five demographic control variables (i.e., age, gender, education, household income and the household's decision maker) were also considered as they may influence the intensity of purchase intention across nations.

Therefore, this study served two purposes: (1) to develop a global conceptual model for sport sponsorship outcomes (i.e., sponsorship awareness, sponsorship fit, attitude toward the sponsor, gratitude, and purchase intentions) and (2) to empirically test the global conceptual model, controlling for age, gender, education, household income and the household's decision maker. The research initiatives were addressed by analyzing soccer fans from the United States (U.S.), the United Kingdom (U.K.), and India in the area of sport sponsorship through a jersey sponsorship.

\section{Literature Review and Hypotheses Development}

\subsection{Sponsorship Awareness}

The consumers' capability to recognize the brand under different conditions has been termed brand awareness, and is considered an important component to companies (Keller, 1993). However, awareness may be country-dependent and therefore, less useful in a global environment (Amis \& Cornwell, 2005). To illustrate, Ko, Kim, Claussen, and Kim (2008) found a positive relationship between awareness and purchase intentions in South Korea, which was consistent with those of previous sponsorship awareness and purchase intentions studies conducted in the U.S. (cf. Maxwell \& Lough, 2009). In contrast, Biscaia and colleagues (2013) did not find any significant effect between awareness and purchase intentions in Portugal.

One of Hofstede, Hofstede, and Minkov's (2010) widely discussed cultural dimensions, the individualism/collectivism dimension, can further elucidate sponsorship awareness. This dimension conveys that individualist cultures tend to be characterized by loose relationships between people (e.g., out-groups), while collectivist cultures have stronger ties between people (e.g., in-groups). For example, the U.S. and the U.K. are considered individualist cultures, while India is a collectivist culture (Hofstede et al., 2010). As such, we might expect to see individuals in collectivist cultures (i.e., India) to be more observant to the manner in which sponsors act as in-group members for the benefit of the group because, normally, the sponsors are perceived as aiding the sport event/team in accomplishing their goals (Gwinner, 2005). Thus, a sponsor's in-group status should aid fans in correctly recognizing a team's sponsors, which then can have a reciprocal positive influence on attitude toward the sponsors, as the favorable attitudes sport fans have toward their peers can extend to team sponsors (Gwinner \& Swanson, 2003).

Moreover, people of collectivist cultures, familiar with symbols, signs, and indirect communication, will process information in a different way than people of individualist cultures, who are more verbally oriented and accustomed to explanations and rhetoric (De Mooij \& Hofstede, 2011). Also, companies from Japan and Korea (i.e., collectivist countries) display corporate identity logos in their television advertisements more frequently than do companies from the U.S. and Germany (i.e., individualist countries; Hofstede et al., 2010). This is because companies from collectivistic countries generally emphasize corporate brands, which inspire trust among consumers and persuade them to buy (De Mooij \& Hofstede, 2010). In light of the above information, one would expect that having a corporate logo on a soccer team jersey would be valued more in collectivist cultures than in individualist cultures, because companies from individualist countries put a focus on product brands with unique characteristics, not on corporate brands (De Mooij \& Hofstede, 2010) Therefore, it can be hypothesized that fans from collectivist cultures (i.e., India) will be more aware of corporate logos, and thus more prone to buy the jersey sponsor's products than fans from individualist cultures (i.e., the U.S., the U.K.).

Thus, the above findings prompted the following hypotheses:

H1: The association between sponsorship awareness and attitudes toward the sponsor will have different effects across American, British, and Indian sport consumers. 
H2: The association between sponsorship awareness and purchase intentions will have different effects across American, British, and Indian sport consumers.

\subsection{Sponsorship Fit}

The concept of fit indicates the relatedness, similarity, relevance, or congruence of event-sponsor relationships (Poon \& Prendergast, 2006). When it comes to sponsorship fit, considerations should be also based on the location and culture in which an investment is made. In individualist cultures, brands have to be unique and distinct with consistent characteristics, whereas in collectivist cultures the brand should be viewed as being part of a larger whole and a product of a trusted company (De Mooij \& Hofstede, 2010). Likewise, children from China (i.e., a collectivist culture) will group products together that share a relationship, whereas children from Canada (i.e., an individualist culture) will group products together that share a category (Hofstede et al., 2010). Such findings help to explain the possible cultural variation in the relationship between sponsorship fit and attitude toward the sponsor. As such, American and British soccer fans can view a sponsor's brand as not fitting well with the team brand because the two should be unique and share a category (e.g., a sport equipment company and a soccer team), while highly identified Indian soccer fans can view a fit between the sponsor's brand and the team's brand in terms of the overall relationship or trust in the sponsor. Hence, Indian sport fans are expected to see a higher fit between team and sponsor, and thus have a higher attitude toward the sponsor and a higher propensity to buy a sponsor's products than American and British sport fans, as the emphasis on brands fitting with companies in collectivist countries means building positive relationships/attitudes among consumers in a company, which then influences them to buy its products (De Mooij \& Hofstede, 2010).

Therefore, we propose in the current study that:

H3: The association between sponsorship fit and attitude toward the sponsor will have different effects across American, British, and Indian sport consumers.

H4: The association between sponsorship fit and purchase intentions will have different effects across American, British, and Indian sport consumers.

\subsection{Attitude toward the Sponsor}

Attitude is defined as "a learned predisposition to respond in a consistently favorable manner with respect to a given object" (Fishbein \& Ajzen, 1975, p. 6). The attitudes toward various sponsor categories may vary across countries, with a potential area of concern being jersey sponsorship. In North America, some fans consider jersey sponsorship on game uniforms an "untouchable territory" that should remain free from financial exploitation (Lukas, 2009). However, Jensen, Bowman, Wang, and Larson (2012) showed that fans of Major League Soccer (MLS) reacted positively to shirt advertisements if it resulted in lower ticket prices and helped MLS teams attract/retain top players. In addition to the status quo of jersey sponsors in soccer, one possible explanation for the acceptance of a sponsor on a team's official game jersey could be that all three analyzed countries score below average on the uncertainty avoidance cultural dimension, and thus there is a fair degree of acceptance for new ideas, innovative products and a willingness to try something new or different (Hofstede et al., 2010). Nevertheless, fans from the U.S. can have a negative attitude toward a jersey sponsor compared with Indian and British fans, as the U.S. has a short-term orientation cultural dimension, which means that although people from the U.S. have a respect for [sports] traditions (Hofstede et al., 2010), they prefer the status quo, which is to not have a sponsor on a team's jersey (Lukas, 2009).

Following the above propositions from previous research, it is hypothesized that:

H5: The association between attitude toward the sponsor and purchase intentions will have different effects across American, British, and Indian sport consumers.

\subsection{Gratitude}

Algoe, Gable, and Maisel (2010) defined gratitude as an emotional appreciation response for costly, yet intentionally provided, benefits from another individual. Kim et al. (2010) found that feelings of gratitude significantly predicted consumers' intent to purchase the benefactor's products in the U.S., as gratitude is a powerful force that motivates a grateful beneficiary to react positively to the benefactor (Palmatier, Jarvis, Bechkoff, \& Kardes, 2009).

However, the location of Kim and colleagues' (2010) study, the U.S., may have been impacted by national culture, as trust, which is linked to gratitude (Palmatier et al., 2009), has been found to be influenced by national culture (Doney, Cannon, \& Mullen, 1998; Schumann et al., 2010). Also, Doney et al. (1998) and Schumann et al. (2010) revealed positive correlations between countries with a high power distance cultural dimension (i.e., the 
level of acceptance of the hierarchical distribution of power) and calculative-, predictive- and capability-based trust building processes (i.e., India). In addition, the academic literature implies a strong positive relationship between trust and collectivism, and a negative relationship between trust and individualism (e.g., Huff \& Kelley, 2005). Therefore, gratitude can have a better relationship with collectivist countries than with individualist countries. It would seem that collectivists, who appear to place more importance on relationships and nurture them with more care than individualists, would have higher levels of trust than individualists (Huff \& Kelley, 2005), and hence, higher levels of gratitude. Furthermore, in collectivist societies, people expect their in-group (which include sponsors) to look after them (Gwinner \& Swanson, 2003). In exchange for this in-group support, one can feel absolute gratitude is owed to another (Hofstede et al., 2010). Consequently, elevated feelings of trust with Indian sport fans for their in-group members (i.e., sponsors), and therefore gratitude, can lead to greater purchase behaviors of sponsor's products than sport fans from individualist countries (i.e., the U.S., the U.K.), as gratitude leads to commitment (Kim et al., 2010; Palmatier et al., 2009). Thus, we posit:

H6: The association between gratitude and purchase intentions will have different effects across American, British, and Indian sport consumers.

\subsection{Purchase Intentions}

According to Spears and Singh (2004), purchase intentions refer to the person's conscious plan in exerting an effort to purchase a brand. From a sponsor's perspective, the purchase intention of a consumer is the most useful indicator of sponsorship effectiveness given its impact on future sales (Choi, Tsuji, Hutchinson, \& Bouchet, 2011).

However, considering culture's ability to influence an individual's personality, which in turn modifies consumer behavior, and bearing in mind that most aspects of consumer behavior are culture-bound (De Mooij \& Hofstede, 2011), culture may impact purchase intentions in distinct areas differently. Indulgence cultures (i.e., the U.S., the U.K.) are characterized by a perception that one can act as one pleases, spend money, and indulge in leisurely and fun-related activities, while restraint cultures (i.e., India) are distinguished by a feeling that enjoyment of leisurely activities, spending, and other similar types of indulgence are somewhat wrong (Hofstede et al., 2010). Thus, American and British sport fans have the potential to show higher purchase intentions values for a sport team's sponsors than Indian sport fans.

Nevertheless, if one examines Hofstede's other cultural dimensions, in low power distance cultures (i.e., the U.S., the U.K.), decision-making is more information-based as people consciously gather information before buying. In high power distance cultures, as in collectivist cultures (i.e., India), one's clothes, shoes, and posture define position in the social hierarchy, and external appearance is important to acquire respect from others (Hofstede et al., 2010). In addition, the greater pressure to conform to the in-groups that prevails in collectivist countries can affect consumer behavior, while members of individualist cultures are less likely to be pressured to buy brands that are not meaningful to them (Foscht et al., 2008). So, since sponsors can be considered in-group members, and there is a greater pressure to agree to the in-group when it comes to consumer behavior in collectivist cultures (Foscht et al., 2008; Gwinner, 2005), Indian sport fans have the potential for higher purchase intentions values than American and British sport fans. The hypothesized model guiding this research is presented in Figure 1. 


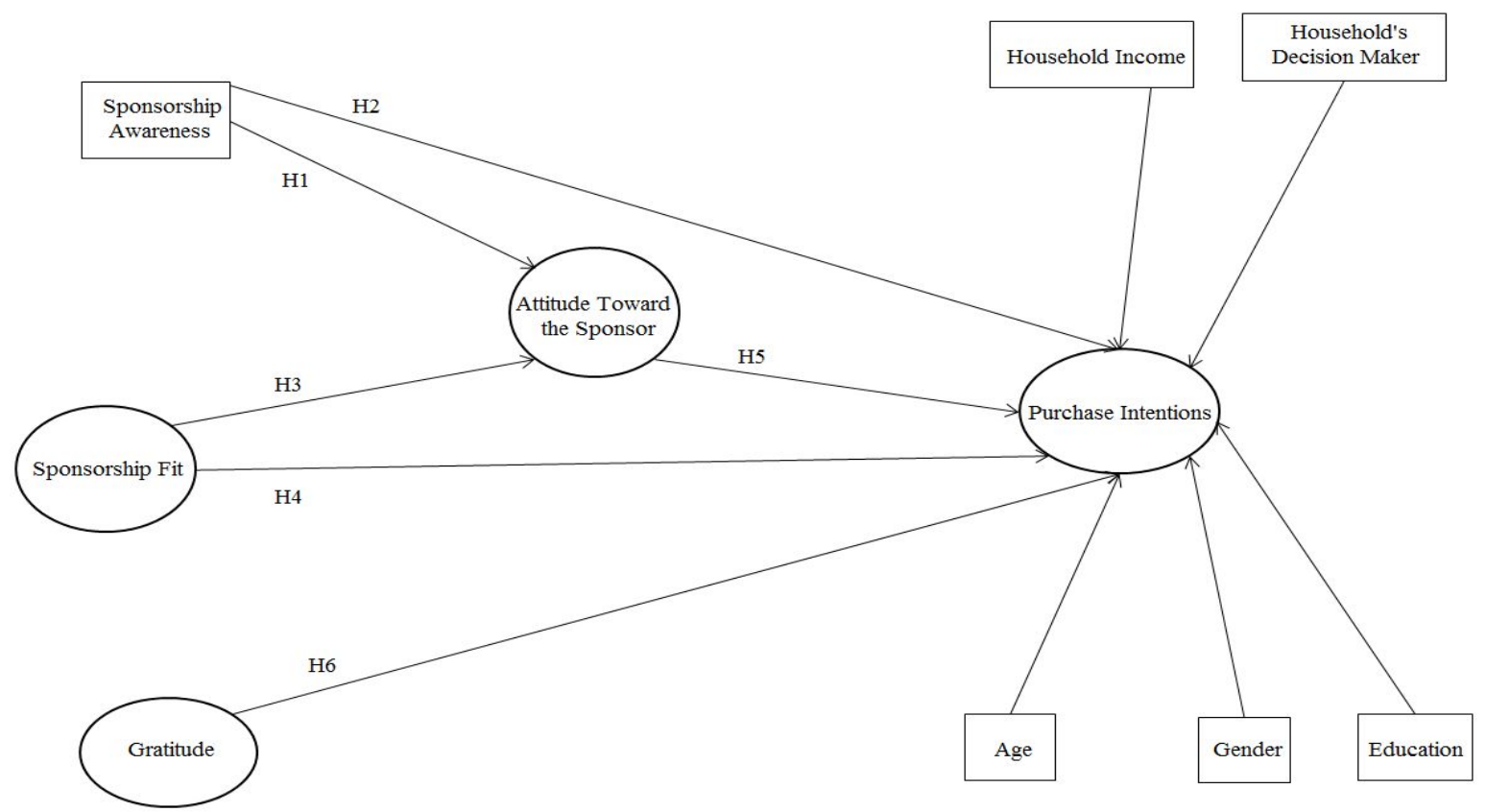

Figure 1. Hypothesized model

\section{Method}

To measure sponsorship outcomes and effectiveness, a survey was utilized where participants rated the effectiveness of Chelsea Football Club's (CFC) jersey sponsorship. In addition, the use of actual sponsors, rather than abstract sponsors, should be a central theme in sponsorship research because sport fans may have varying attitudes and intentions toward different companies, teams, and sports (Biscaia et al., 2013).

The jersey sponsor for this study will not be identified, due to proprietary information and to ensure inscrutability, but it is a multi-national company that sells products such as computers, televisions, mobile phones, printers and refrigerators, and is the largest information technology company in the world (Grobart, 2013).

\subsection{Participants and Data Collection}

The online questionnaire was conducted in English, due to it being the most commonly used language in the selected countries. The survey link was advertised to administrators of CFC's official supporter clubs, which were identified from the official CFC website, and were located in the U.S., the U.K., and India. The survey link was also posted on CFC's official supporter clubs' Facebook pages, Twitter accounts, and forums of these three countries.

The survey remained active for 18 weeks, at which time a total of 694 surveys were collected. The survey software allowed just one response to be recorded from each Internet protocol (IP) address, preventing participants from taking the survey more than once. The researchers removed 76 questionnaires that were completed by CFC fans from countries other than the three that were analyzed, as indicated from the demographic portion of the survey regarding the participant's country of residence. Incomplete information eliminated 96 surveys by American, British and Indian CFC fans. This resulted in 522 usable surveys, which were collected from American $(n=230)$, British $(n=126)$ and Indian $(n=166)$ CFC fans. The profile of the respondents by country is shown in Table 1 . 
Table 1. Demographic characteristics of respondents

\begin{tabular}{|c|c|c|c|}
\hline \multirow[b]{2}{*}{ Demographic variable } & \multicolumn{2}{|l|}{ Country } & \multirow[b]{2}{*}{ INDIA } \\
\hline & U.S. & U.K. & \\
\hline \multicolumn{4}{|l|}{ Gender } \\
\hline Male (\%) & 87.83 & 92.86 & 95.18 \\
\hline Female (\%) & 12.17 & 7.14 & 4.82 \\
\hline \multicolumn{4}{|l|}{ Age } \\
\hline $18-34(\%)$ & 66.52 & 49.21 & 97.59 \\
\hline $35-54(\%)$ & 29.57 & 38.89 & 1.20 \\
\hline 55 and over $(\%)$ & 3.91 & 11.90 & 1.21 \\
\hline \multicolumn{4}{|l|}{ Education } \\
\hline High School or Some College (\%) & 29.57 & 40.48 & 14.46 \\
\hline Undergraduate Degree (\%) & 50.43 & 46.83 & 56.02 \\
\hline Graduate Degree (\%) & 20.00 & 12.69 & 29.52 \\
\hline \multicolumn{4}{|l|}{ Annual Household Income } \\
\hline Less than $\$ 20,000(\%)$ & 13.04 & 21.43 & 53.61 \\
\hline$\$ 20,000-\$ 59,999(\%)$ & 30.43 & 31.75 & 39.16 \\
\hline$\$ 60,000-\$ 89,999(\%)$ & 19.57 & 23.81 & 2.41 \\
\hline$\$ 90,000$ or more $(\%)$ & 36.96 & 23.01 & 4.82 \\
\hline \multicolumn{4}{|l|}{ Employment Status } \\
\hline Employed (\%) & 64.78 & 57.14 & 41.57 \\
\hline Unemployed (\%) & 7.39 & 7.14 & 4.82 \\
\hline Self-employed (\%) & 7.83 & 13.49 & 11.45 \\
\hline Retired (\%) & 1.00 & 4.76 & 0.06 \\
\hline Student $(\%)$ & 18.70 & 15.08 & 40.96 \\
\hline Other $(\%)$ & 0.29 & 2.39 & 1.14 \\
\hline \multicolumn{4}{|l|}{ Household's Decision Maker } \\
\hline Yes (\%) & 45.65 & 42.06 & 20.48 \\
\hline No $(\%)$ & 54.35 & 57.94 & 79.52 \\
\hline
\end{tabular}

\subsection{Measures}

The online survey included items adapted from previously validated surveys to measure five areas: sponsorship awareness via unaided recall (Walsh, Kim, \& Ross, 2008), sponsorship fit (Gwinner \& Bennett, 2008), attitude toward the sponsors (Gwinner \& Bennett, 2008), gratitude (Palmatier et al., 2009), and purchase intentions (Gwinner \& Bennett, 2008). Slight modifications were made to suit the specific needs of this study. The items were arranged in the same order for all three countries and contained identical designs. Previous results indicated that unaided recall is more accurate than aided recall when assessing sponsorship awareness (cf. Biscaia et al., 2013), and as such this research examined only unaided recall. In order to accurately test respondents' knowledge of CFC's jersey sponsor in the online survey, and to reduce outside Internet searches, the subjects had to input the jersey sponsor within 20 seconds before being automatically re-directed to the next survey page. Responses were scored from 0 , meaning no recall of jersey sponsor, to 1 , unaided recall of the jersey sponsor. This study also employed five control demographic variables; descriptive statistics for these demographics appear in Table 1.

This research used naturally opposing and mutually exclusive scale anchors, as Harzing, Reiche and Pudelko (2013) found that anchor scales encourage international respondents to connect fully with the questions. Also, Clarke III (2001) recommended scales with more categories as appropriate for cross-national research, thus this study used Likert-type scales with 10 categories, anchored by 'Strongly Disagree' (1) and 'Strongly Agree' (10). In addition, the attentiveness of survey participants was tested by inserting the statement "On this question please click on 'Strongly Agree' so we can ensure you are paying attention" in one of the sponsorship outcomes' items.

\subsection{Data analysis}

Data were analyzed using Statistical Package for the Social Sciences (SPSS) 21 and AMOS 21. Before any analyses were conducted, the normality of the data were assessed by looking at skewness and kurtosis values. First, to assess the measurement model for each country, a CFA was conducted. Internal consistency of the constructs was measured through composite reliability (CR; Hair, Black, Babin, \& Anderson, 2009). Convergent validity was evaluated through the average variance extracted (AVE), while discriminant validity was established when AVE for each construct exceeded the squared correlations between that and any other construct (Fornell \& Larcker, 1981). Second, in order for country comparisons to be meaningful, the instruments used to measure the constructs of interest have to display adequate cross-national equivalence (De Beuckelaer, 2005). The researchers used the MGCFA model, as MGCFA is the leading approach to inspect cross-national 
measurement invariance (Behling \& Law, 2000). Third, to assess the structural models and invariance of the proposed model across all three countries, the researchers utilized MGSEM (Byrne, 2010) with purchase intentions as the endpoint of sponsorship effectiveness.

\section{Results}

The skewness values for the items used in this study ranged from -2.96 to 1.54 , while the kurtosis values ranged from -1.70 to 6.77 . Following Hair and colleagues' (2009) suggestion that only variables with skew index absolute values greater than 3 and kurtosis index absolute values greater than 10 are of concern, these values were considered normal and would not limit the use of factor analysis.

\subsection{Measurement Model}

The results of the CFA in the model for each country showed that the standardized factor loadings ranged from .58 to .98 (the U.S.), from .71 to .98 (the U.K.), and from .62 to .93 (India), and were all significant ( $p$ $<.001$ ), hence surpassing the cut-off point of .50 (Hair et al., 2009). As shown in Table 2, all the CR values ranged from .87 to .94 (the U.S.), from .88 to .95 (the U.K.), and from .76 to .90 (India), indicating acceptable levels of reliability for the constructs, according to the recommended .70 threshold (Hair et al., 2009). Moreover, all AVE values were equal to or greater than the .50 standard for convergent validity (Fornell \& Larcker, 1981), ranging from .62 to .84 (the U.S.), from .66 to .87 (the U.K.), and from .50 to .70 (India), indicating acceptable levels of convergent validity for the constructs. In addition, discriminant validity of the measures was accepted given that the AVE for each construct is greater than the squared correlation between the construct and other constructs in the model (Fornell \& Larcker, 1981). Table 3 lists additional descriptive statistics (i.e., mean and standard deviations) and the correlation matrix, with the correlations among constructs and the square root of AVE on the diagonal. The four diagonal elements of the latent variables for every country were all larger than their corresponding correlation coefficients, which indicated that the metrics had appropriate discriminant validity.

Table 2. Factor Loadigs, Composite Reliability (CR), and Average Variance Extracted (AVE)

\begin{tabular}{|c|c|c|c|c|c|c|c|c|c|}
\hline \multirow[b]{2}{*}{ Constructs/items } & \multicolumn{3}{|c|}{ U.S. } & \multicolumn{3}{|c|}{ U.K. } & \multicolumn{3}{|c|}{ INDIA } \\
\hline & Loading $^{\mathrm{b}}$ & $\mathrm{CR}$ & AVE & Loading $^{\mathrm{b}}$ & $\mathrm{CR}$ & AVE & Loading $^{\mathrm{b}}$ & $\mathrm{CR}$ & AVE \\
\hline Sponsorship Fit ${ }^{a}$ & & .87 & .62 & & .88 & .66 & & .80 & .50 \\
\hline There is a close fit between $<$ sponsors name $>$ and $<$ team name $>$ & .807 & & & .914 & & & .702 & & \\
\hline$<$ Sponsor name $>$ and $<$ team name $>$ have many similarities & .832 & & & .858 & & & .727 & & \\
\hline It makes sense that $<$ sponsor name $>$ sponsors $<$ team name $>$ & .801 & & & .706 & & & .617 & & \\
\hline My image of $<$ team name $>$ is consistent with my image of $<$ sponsor name $>$ & .703 & & & .742 & & & .774 & & \\
\hline Atittude Toward the Sponsor ${ }^{\text {a }}$ & & .92 & .78 & & .89 & .73 & & .76 & .51 \\
\hline I like $<$ sponsor name $>$ brand & .942 & & & .898 & & & .842 & & \\
\hline$<$ Sponsor name $>$ is a very good brand of $<$ product-category $>$ & .908 & & & .915 & & & .658 & & \\
\hline I have a favorable disposition/mood toward < sponsor name $>$ & .796 & & & .730 & & & .627 & & \\
\hline Gratitude $^{a}$ & & .94 & .84 & & .95 & .87 & & .87 & .70 \\
\hline I feel grateful to $<$ sponsor name $>$ for its sponsorship to $<$ team name $>$ & .982 & & & .983 & & & .927 & & \\
\hline I feel thankful to <sponsor name $>$ for its sponsorship to $<$ team name $>$ & .946 & & & .979 & & & .902 & & \\
\hline I appreciate $<$ sponsor name $>$ & .807 & & & .818 & & & .647 & & \\
\hline Purchase Intentions ${ }^{\mathrm{a}}$ & & .88 & .66 & & .89 & .67 & & .90 & .70 \\
\hline I will buy a $<$ product-category $>$ made by $<$ sponsor name $>$ & .929 & & & .781 & & & .913 & & \\
\hline Next time I need to buy a < product-category $>$, I would consider buying < sponsor name> & .888 & & & .787 & & & .888 & & \\
\hline I will be more likely to buy a $<$ product-category $>$ made by $<$ sponsor name $>$ over its competitors & .808 & & & .928 & & & .867 & & \\
\hline $\begin{array}{l}\text { The }<\text { sponsor name }>\text { sponsorship to }<\text { team name }>\text { makes me more likely to buy } \\
\text { a }<\text { product-category }>\text { made by }<\text { sponsor name }>\end{array}$ & .585 & & & .756 & & & .661 & & \\
\hline
\end{tabular}

Note:

${ }^{\text {aE}}$ Each item measured on a ten-point Likert-type scale with anchors: 1 = "Strongly Disagree", 10 = "Strongly Agree"

${ }^{\circ}$ All factor loadings are significant at $p<.001$

Model fit (U.S.): $\chi^{2}(81)=209.821, p<.001, \chi^{2} / d f=2.590, \mathrm{TLI}=.94, \mathrm{CFI}=.95, \mathrm{GFI}=.90, \mathrm{RMSEA}=.083$

Model fit (U.K.): $\chi^{2}(81)=155.379, p<.001, \chi^{2} / d f=1.918, \mathrm{TLI}=.94, \mathrm{CFI}=.95, \mathrm{GFI}=.86, \mathrm{RMSEA}=.086$

Model fit (INDIA) $: \chi^{2}(75)=185.590, p<.001, \chi^{2} / d f=2.475, \mathrm{TLI}=.89, \mathrm{CFI}=.92, \mathrm{GFI}=.88, \mathrm{RMSEA}=.095$ 
Table 3. Mean (M), Standard Deviation (SD), and Correlation Matrix

\begin{tabular}{|c|c|c|c|c|c|c|c|c|c|c|c|c|}
\hline \multirow[b]{2}{*}{ Countries/Variables } & \multirow[b]{2}{*}{$\mathrm{M}$} & \multirow[b]{2}{*}{$\mathrm{SD}$} & \multicolumn{10}{|c|}{ Correlation Matrix } \\
\hline & & & 1 & 2 & 3 & 4 & 5 & 6 & 7 & 8 & 9 & 10 \\
\hline \multicolumn{13}{|l|}{ U.S. } \\
\hline 1. Sponsorship Fit & 7.11 & 1.98 & .79 & & & & & & & & & \\
\hline 2. Atittude Toward the Sponsor & 8.35 & 1.64 & .64 & .88 & & & & & & & & \\
\hline 3. Gratitude & 7.24 & 2.22 & .50 & .44 & .91 & & & & & & & \\
\hline 4. Purchase Intentions & 7.71 & 2.13 & .54 & .81 & .36 & .81 & & & & & & \\
\hline 5. Sponsorship Awareness & .92 & .27 & .04 & -.06 & -.03 & -.11 & & & & & & \\
\hline 6. Age & 1.37 & .56 & .11 & .15 & .08 & .20 & -.07 & & & & & \\
\hline 7. Gender & .88 & .33 & .10 & -.01 & .02 & .06 & .14 & -.11 & & & & \\
\hline 8. Education & 1.90 & .70 & .07 & -.06 & -.07 & .03 & .17 & .07 & .06 & & & \\
\hline 9. Household Income & 2.80 & 1.08 & .04 & .07 & -.08 & .09 & .02 & .43 & .09 & .17 & & \\
\hline 10. Household's Decision Maker & .46 & .50 & .06 & -.01 & -.10 & .04 & -.03 & .00 & .10 & .03 & -.03 & \\
\hline \multicolumn{13}{|l|}{ U.K. } \\
\hline 1. Sponsorship Fit & 6.32 & 2.24 & .81 & & & & & & & & & \\
\hline 2. Atittude Toward the Sponsor & 7.85 & 1.69 & .59 & .85 & & & & & & & & \\
\hline 3. Gratitude & 6.14 & 2.47 & .64 & .43 & .93 & & & & & & & \\
\hline 4. Purchase Intentions & 6.69 & 2.38 & .61 & .73 & .53 & .82 & & & & & & \\
\hline 5. Sponsorship Awareness & .86 & .35 & .09 & .00 & -.03 & .04 & & & & & & \\
\hline 6. Age & 1.63 & .69 & .07 & -.03 & .14 & .06 & .04 & & & & & \\
\hline 7. Gender & .93 & .26 & -.02 & .05 & .05 & -.05 & .06 & -.15 & & & & \\
\hline 8. Education & 1.72 & .68 & -.25 & -.16 & -.15 & -.06 & .07 & .02 & .07 & & & \\
\hline 9. Household Income & 2.48 & 1.07 & -.18 & .04 & -.09 & .01 & .04 & .26 & .10 & .28 & & \\
\hline 10. Household's Decision Maker & .42 & .50 & .01 & .05 & .10 & .13 & -.11 & .18 & -.14 & .01 & .05 & \\
\hline \multicolumn{13}{|l|}{ INDIA } \\
\hline 1. Sponsorship Fit & 7.44 & 1.88 & .71 & & & & & & & & & \\
\hline 2. Atittude Toward the Sponsor & 8.38 & 1.49 & .60 & .72 & & & & & & & & \\
\hline 3. Gratitude & 8.00 & 1.77 & .53 & .41 & .83 & & & & & & & \\
\hline 4. Purchase Intentions & 7.75 & 2.15 & .52 & .70 & .36 & .84 & & & & & & \\
\hline 5. Sponsorship Awareness & .92 & .27 & .02 & .12 & -.07 & .10 & & & & & & \\
\hline 6. Age & 1.04 & .24 & .12 & -.03 & .01 & .03 & -.05 & & & & & \\
\hline 7. Gender & .95 & .22 & -.03 & -.12 & .09 & -.08 & .04 & .03 & & & & \\
\hline 8. Education & 2.15 & .65 & -.02 & .11 & .07 & .11 & .03 & .08 & -.21 & & & \\
\hline 9. Household Income & 1.58 & .76 & .02 & .01 & .08 & .03 & .05 & -.08 & -.12 & .19 & & \\
\hline 10. Household's Decision Maker & .20 & .40 & .16 & .07 & .13 & .11 & -.02 & -.01 & .05 & .07 & .00 & \\
\hline
\end{tabular}

Note:

Diagonals in bold are square root of AVE.

In accordance with the aim of this study, the results of the final measurement model using the U.S. $\left[\chi^{2}(81)=\right.$ $\left.209.821, p<.001, \chi^{2} / \mathrm{df}=2.590, \mathrm{TLI}=.94, \mathrm{CFI}=.95, \mathrm{GFI}=.90, \mathrm{RMSEA}=.083\right]$, the U.K. $\left[\chi^{2}(81)=155.379, p\right.$ $\left.<.001, \chi^{2} / \mathrm{df}=1.918, \mathrm{TLI}=.94, \mathrm{CFI}=.95, \mathrm{GFI}=.86, \mathrm{RMSEA}=.086\right]$, and India $\left[\chi^{2}(75)=185.590, p<.001\right.$, $\left.\chi^{2} / \mathrm{df}=2.475, \mathrm{TLI}=.89, \mathrm{CFI}=.92, \mathrm{GFI}=.88, \mathrm{RMSEA}=.095\right]$ showed an acceptable fit to the data. Although the chi-square goodness of fit index was statistically significant, in general, chi-square-based statistics can be misleading (Schumacker \& Lomax, 2010). The values for the additional fit indices were close or exceeded the critical values for good model fit, as CFI, TLI and GFI values higher than .90 are considered to have a close fit (Hair et al., 2009). However, TLI and GFI values are sensitive to sample size and, therefore, researchers need to be cautious with interpretation when assessing model fit (Hu \& Bentler, 1999). This study's RMSEA values were slightly over this estimate, as $\mathrm{Hu}$ and Bentler (1999) suggested RMSEA values between .05 and .08 to indicate a fair fit, but recent research cautioned about using precise cutoff points for RMSEA (cf. Chen, Curran, Bollen, Kirby, \& Paxton, 2008), so the values were considered acceptable.

\subsection{Measurement Invariance}

In a comparative study, it is important that the constructs are equally relevant (or are invariant) to the samples in different countries included in this research. The chi-square difference test between the unconstrained model and the constrained model $\left(\Delta \chi^{2}=111.063, \Delta d f=42, p<.001\right)$ was significant, indicating that the restricted model failed the test of measurement invariance across countries. However, scholars proposed the use of alternative goodness-of-fit indexes to assess measurement invariance (Cheung \& Rensvold, 2002; Hu \& Bentler, 1999). Cheung and Rensvold (2002) found in simulation studies that among many goodness-of-fit indexes, CFI has performed better than other indexes available in structural equation modeling software, and have suggested that a difference of equal to or less than .01 in CFI between two nested models would indicate measurement invariance. The difference in the CFI between the unconstrained model $(\mathrm{CFI}=.926)$ and the constrained model $(\mathrm{CFI}=.920)$ was only .006, indicating invariance. Hu and Bentler (1999) suggested that point estimates and confidence 
intervals of RMSEA should be also used to compare the unconstrained and constrained models. If point estimates are very close, and confidence intervals have large overlaps, then measurement invariance can be assumed. The point estimates of RMSEA and the RMSEA confidence intervals are almost matching for the unconstrained model (RMSEA $=.048 ; 90 \% C I=.045, .051)$ and the constrained model (RMSEA $=.047 ; 90 \%$ $C I=.044, .050)$. Therefore, the researchers were confident to assume measurement invariance between the unconstrained and the constrained models, considering the small differences in the above goodness-of-fit indexes.

\subsection{Structural Models}

The examination of the structural models included a test of the overall model fit, as well as individual tests of the relationships among constructs for each country. The

overall assessment of the structural models indicated an acceptable fit to the data for the U.S. $\left[\chi^{2}(26)=60.972, p\right.$ $<.001, \chi^{2} / \mathrm{df}=2.345, \mathrm{TLI}=.86, \mathrm{CFI}=.92, \mathrm{GFI}=.95$, RMSEA $\left.=.077\right]$, the U.K. $\left[\chi^{2}(26)=39.946, p<.039\right.$, $\left.\chi^{2} / \mathrm{df}=1.536, \mathrm{TLI}=.90, \mathrm{CFI}=.94, \mathrm{GFI}=.94, \mathrm{RMSEA}=.066\right]$, and India $\left[\chi^{2}(26)=42.699, p<.021, \chi^{2} / \mathrm{df}=1.642\right.$, $\mathrm{TLI}=.85, \mathrm{CFI}=.92, \mathrm{GFI}=.96, \mathrm{RMSEA}=.062]$.

Figure 2 shows the standardized regression coefficients for the structural models of all three countries. Sponsorship awareness showed a direct positive effect only for India, and in all three models sponsorship awareness was not significant on attitude toward the sponsor $\left(\beta_{\mathrm{U} . \mathrm{S} .}=-.08, p=.107 ; \beta_{\mathrm{U} . \mathrm{K} .}=-.06, p=.414\right.$; $\beta_{\mathrm{INDIA}}$ $=.12, p=.089)$. Moreover, sponsorship awareness had a direct positive effect for only two countries, and was not significant on purchase intentions $\left(\beta_{\mathrm{U} . \mathrm{S}}=-.09, p=.056 ; \beta_{\mathrm{U} . \mathrm{K} .}=.04, p=.465 ; \beta_{\mathrm{INDIA}}=.05, p=.402\right)$ when controlling for age, gender, education, household income and household's decision maker in all three models. Sponsorship fit had a direct effect on all three countries and was significant on its relationships with attitude toward the sponsor $\left(\beta_{\mathrm{U} . \mathrm{S} .}=.60, p<.001 ; \beta_{\mathrm{U} . \mathrm{K} .}=.59, p<.001 ; \beta_{\mathrm{INDIA}}=.46, p<.001\right)$ in all three models. Also, sponsorship fit had a direct effect on all three countries and was significant in its relationships with purchase intentions $\left(\beta_{\mathrm{U} . \mathrm{S}}=.15, p=.012 ; \beta_{\mathrm{U} . \mathrm{K} .}=.17, p=.042 ; \beta_{\mathrm{INDIA}}=.18, p=.013\right)$ when controlling for age, gender, education, household income and household's decision maker in all three models. Attitude toward the sponsor showed a strong direct effect on all three countries and was significant in its relationships with purchase intentions $\left(\beta_{\text {U.S. }}=.55, p<.001 ; \beta_{\text {U.K. }}=.51, p<.001 ; \beta_{\text {INDIA }}=.50, p<.001\right)$ when controlling for age, gender, education, household income and household's decision maker in all three models. The associations between gratitude and purchase intentions was significant only in the U.S. and the U.K. and showed a direct positive effect when controlling for age, gender, education, household income and household's decision maker in each analyzed country $\left(\beta_{\mathrm{U} . \mathrm{S}}=.14, p=.005 ; \beta_{\mathrm{U} . \mathrm{K} .}=.21, p=.006 ; \beta_{\mathrm{INDIA}}=.12, p=.069\right)$.

Jointly, sponsorship awareness, sponsorship fit, attitude toward the sponsor, and gratitude accounted for $54 \%$ of the variance of purchase intentions regarding the U.S. $\left(R^{2}=.54\right), 58 \%$ concerning the U.K. $\left(R^{2}=.58\right)$, and $44 \%$ concerning India $\left(R^{2}=.44\right)$, when controlling for the demographic variables. These five control variables were regressed on the endogenous variable of purchase intentions, however, their individual effect was not found significant in each analyzed country. 


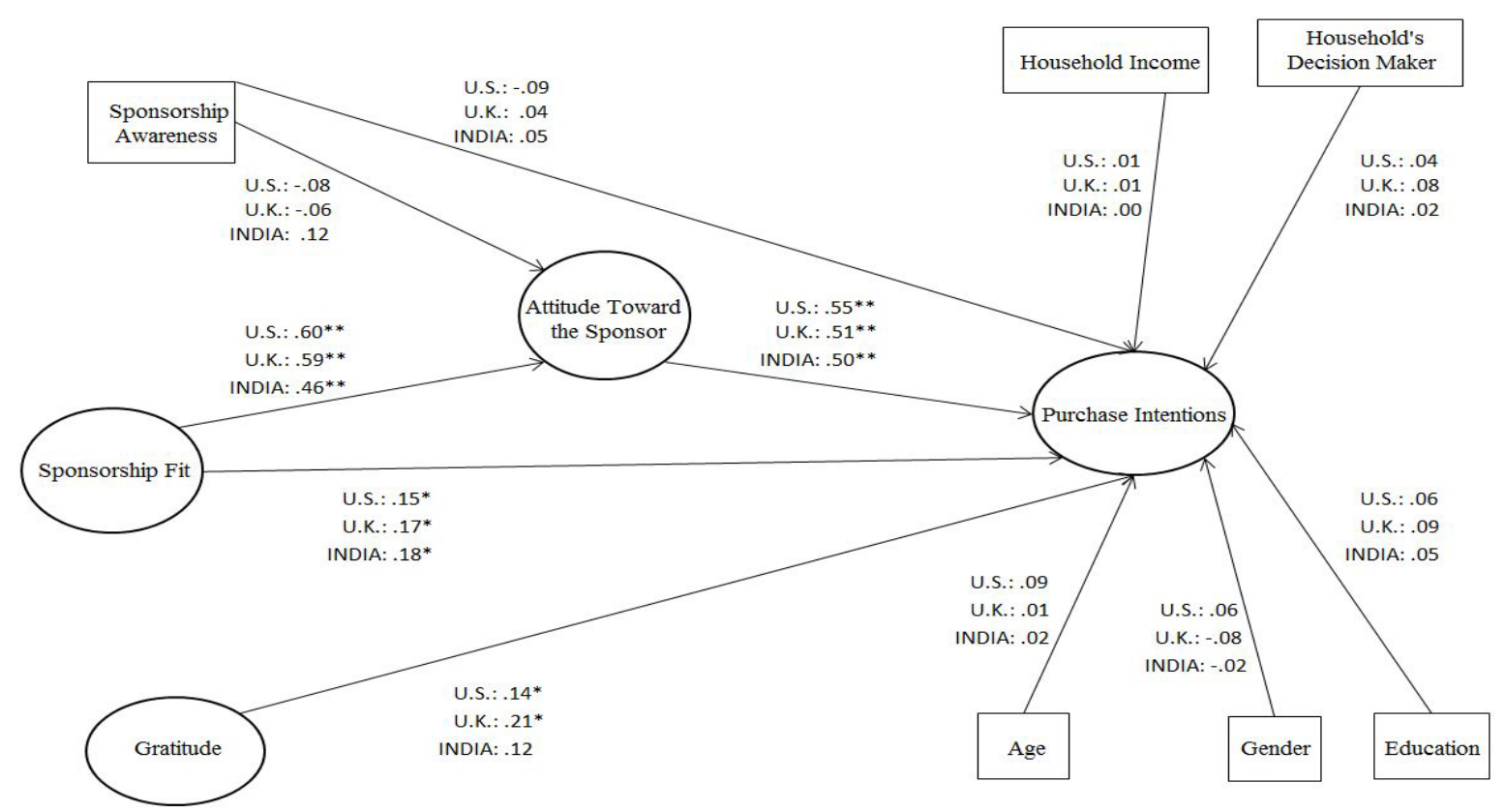

Figure 2. Standardized estimates of the structural models

Notes. ${ }^{*} p \leqq .001,{ }^{*} p<.05$.

\subsection{Structural Invariance}

MGSEM was used, according to the procedures described by Byrne (2010), to assess the structural invariance of the hypothesized model across all three countries in order to distinguish if the associations among sponsorship outcomes and control variables will have significant different effects across the three analyzed countries.

In the unconstrained model, structural relationships (i.e., regression coefficients) were freely estimated for each country. In the constrained model, all parameters were forced to be equal for all three countries. The test of chi-square difference showed that there was no statistical difference between the unconstrained and the constrained model $\left(\Delta \chi^{2}=19.498, \Delta d f=33, p=.970\right)$. Moreover, the difference in the CFI between the unconstrained model $(\mathrm{CFI}=.940)$ and the constrained model $(\mathrm{CFI}=.948)$ was only .008 , indicating invariance. Also, results indicated that when all regression coefficients were fixed to be invariant across countries (the constrained model), the model still fit the data very well, and the RMSEA confidence intervals for the unconstrained model (RMSEA $=.032 ; 90 \% C I=.026, .038$ ) and the constrained model (RMSEA $=.026 ; 90 \% C I$ $=.020, .031)$ were overlapping. Therefore, structural relationships among sponsorship outcomes and control variables were invariant among all three countries; thus, the six hypotheses were not supported.

\section{Discussion and Implications}

Despite a growing interest in determining how sponsorship outcomes function at a global level (Amis \& Cornwell, 2005), few researchers have pursued such an investigation (Amis \& Cornwell, 2005; Santomier, 2008), highlighting the significance of this inquiry. The results acknowledged, for the first time, the measurement and structural invariance of a global sport sponsorship model. This suggests that the causal relationships among sport sponsorship outcomes may be impervious to Hofstede and colleagues' (2010) cultural dimensions theory. This outcome is most probably due to the fact that data was collected from a homogenous group: Fans of official supporter clubs. Presumably, these fans are alike in their point of view toward the jersey sponsor regardless of their country of origin, and they are more attached to the analyzed team than non-fans because fans display long-term dedication to the team (Sutton, McDonald, \& Milne, 1997), and have a higher likelihood to support event sponsors and purchase from these sponsors (Maxwell \& Lough, 2009). Moreover, respondents' demographics that might have influenced the analyzed sponsorship outcomes were controlled in this analysis and were found not significant, further strengthening the validity of the sponsorship outcomes' causal relationships.

Sponsorship awareness was uniform at an international level, with a vast majority of respondents in each analyzed country recalling the sponsor without prompting (U.S.: 92.17\%; U.K.: 85.71\%; India: 92.17\%). Therefore, sponsorship campaigns, such as jersey sponsorships, may be equally effective in building brand 
awareness among fans from individualist countries and collectivist countries despite companies being rooted in different cultures and having diverse strategies in marketing their brands (De Mooij \& Hofstede, 2010). Still, results did not support hypotheses $\mathrm{H} 1$ and $\mathrm{H} 2$, which posited that sponsorship awareness may have a different influence on fan attitudes toward the sponsor, or on purchase intentions, across nations. In addition, sponsorship awareness was not a predictor of attitudes toward the sponsor or purchase intentions. It seems that there is no need to identify a company as a sponsor of an event for a sponsorship message to be effective (Amis \& Cornwell, 2005 ) as there is no certainty that a fan's opinion of the sponsor is likely to change (Woodside \& Summers, 2012) even if the sponsor is recollected at a cross-national level. Moreover, while this study and previous research has revealed that a sponsorship is capable of creating awareness (e.g., Ko et al., 2008), there is no conclusive evidence that awareness prompts purchase intentions (Woodside \& Summers, 2012). Given that the majority of companies who are involved with sponsorship have a primary objective to increase brand awareness (Ko et al., 2008), the findings from this study are particularly valuable. For sponsorship managers, this means that solely measuring awareness is not adequate when evaluating the effectiveness of sponsorship at a cross-national level. Thus, a sponsorship activity that fails to connect a fan and sponsor beyond an awareness stage will not improve attitudes towards a sponsor's brand, nor engender purchase intentions.

The relationship between sponsorship fit and attitude toward the sponsor was found to be statistically significant for all three countries, as was the association between sponsorship fit and purchase intentions. Interestingly, Close and Lacey (2013) found a positive relationship between degree of fit and respondents' interest in the sponsor, attitude toward the sponsor, or intention to use the sponsored product, confirming past studies from individualist countries. These previous findings are not surprising, as people in individualist countries will group brands together that share a category (De Mooij \& Hofstede, 2010). Yet, contrary to cultural dimensions theory, the structural relationships of sponsorship fit with attitude toward the sponsor and with purchase intentions were significant for every country in this study, despite the CFC's sponsor not having any natural perceived fit with the team or with the sport of soccer. However, the current study's results can be explained by arguing that it is not necessary to find a strong link between the team and the sponsor at an international level, so long as marketers are able to articulate a positive relationship between the two (Olson \& Thjømøe, 2011). For instance, companies that sponsor a team may wish to incorporate corporate social responsibility (CSR) strategies that include social objectives within sponsorship initiatives (Alexandris et al., 2012) as consumers are more likely to notice and support a fit with socially-oriented companies (Close \& Lacey, 2013).

The relationship between attitude toward the sponsor and purchase intentions was found to also not vary across countries, disputing postulated differences inherent with divergent cultures (Hofstede et al., 2010). In fact, attitude toward the sponsor was found to be the major predictor of purchase intentions for all analyzed countries, confirming the results of previous research on the link between attitude and intentions (cf. Biscaia et al., 2013). Thus, there are unique circumstances related to sport that international corporations should be aware of when they attempt to build more effective international sponsorship-linked marketing initiatives. To illustrate, the favorable opinions fans have for a global company may be enhanced if the affiliations between sponsors and sport teams have the ability to lower ticket prices, reduce team expenses, or assist in attracting/retaining star players (Jensen et al., 2012). This is particularly true in the U.S. for jersey sponsorship, where some professional sport leagues (i.e., Major League Baseball, the National Basketball Association, the National Football League, and the National Hockey League) have yet to implement game-day jersey sponsorships. Even though U.S. based leagues have negotiated very large media agreements that serve to help keep ticket prices from escalating, the researchers believe that the decision to reject the notion of game-day jersey sponsorship should be reevaluated, and the benefits of jersey sponsorship, based on this study's findings, can go beyond the financial gain teams would realize from such an agreement. In fact, based on these results and in light of declining growth in professional sport ticket purchases (Booton, 2013), professional sport leagues in the U.S. should be encouraged to consider jersey sponsorship opportunities.

The structural equation analyses revealed that the association between gratitude and purchase intentions was invariant across countries. Gratitude may not be a predictor of purchase intentions for fans residing in India despite previous research recognizing that elevated levels of trust (which are linked to gratitude and characteristic of collectivist country inhabitants) can lead to future purchase behaviors (e.g., Huff \& Kelley, 2005). However, considering that invariance was accepted for this study's global sport sponsorship model, additional scholarly investigations should examine the reasons for this inconsistency in the relationship between gratitude and purchase intentions.

This potential discrepancy may be explained by the given sport context. In collectivist societies, compared to individualist countries, there is a sharp distinction between members of in-groups and out-groups (Hofstede et al., 
2010). Correspondingly, sport fans evaluate in-group members, including team sponsors, more positively than out-group members (Wann \& Branscombe, 1995), which could possibly make their cultural backgrounds less relevant. Thus, CFC fans from India may still feel that the CFC jersey sponsor belongs to an out-group, explaining why feelings of gratitude toward the sponsor had little influence on a fan's purchase intentions. International companies must be cognizant that they need to include culturally relevant, sponsorship-linked marketing campaigns specific to each country aimed at building stronger relationships, including gratitude relationships, between the team sponsor and, for example, CFC supporter clubs. In addition, India, for example, has a high level of the cultural dimension of power distance (Hofstede et al., 2010), and people in such cultures avoid media that do not allow for face-to-face interaction (Van Slyke, Lou, \& Belanger, 2001). To overcome this issue, Pyun, Kwon, \& Lee (2011) recommended exhibition games as a way to build connectedness with other cultures, as these games could benefit a team or league attempting to expand into Asia. While conducting training camps and exhibition soccer games in international countries can help to overcome national barriers, efforts should also be supported through more culture-centric activations of team sponsors.

Overall, these empirical results confirm that sport and in particular, soccer, can serve as a signifier of identity, and transnational values of soccer sponsors can be shared within different communities and cultures worldwide.

\section{Limitations and Future Research}

First, this study looked only at an international organization, and as such, the results would not apply to small or locally based companies. Second, this study tested the cross-national application of sponsorship outcomes using just one team and sponsor. Future research will require a wider variety of sponsorship contexts, such as different sports, teams, and sponsor levels to test the validity of the research findings. Third, while this research was developed within three local contexts, it might not be applicable to other countries outside of the three that were examined. Thus, researchers should test these findings with more countries where sponsorship has experienced growth, such as China and Brazil. Fourth, the level of team identification for CFC fans was not controlled in these research analyses. However, the researchers targeted only CFC supporter clubs, which, per this study's invariance results, are homogenous groups that would not cast doubt on the validity of the research findings. Moreover, this study's sport fans displayed strong awareness, fit, attitude, and purchase intentions levels toward the sponsor across every analyzed country, which is in concordance with other sport sponsorship studies that have examined highly identified sport fans (e.g., Alexandris et al., 2012; Biscaia et al., 2013; Gwinner \& Bennett, 2008). Fifth, the current study considered only five variables, and other variables may help to further explain sponsorship effectiveness. Future studies ought to test cross-national differences with other sponsorship effects, such as word of mouth, goodwill, and image transfer. Furthermore, future attempts should be made to also include cultural variables in global sponsorship models. Sixth, the data for this research was collected with the use of the purposive sampling method, which can make research methods susceptible to bias. However, the sampling judgments made by the authors were based on clear and analytical criteria in an effort to reduce such bias.

\section{References}

Alexandris, K., Tsiotsou, R. H., \& James, J. D. (2012). Testing a hierarchy of effects model of sponsorship effectiveness. Journal of Sport Management, 26(5), 363-378.

Algoe, S. B., Gable, S. L., \& Maisel, N. C. (2010). It's the little things: Everyday gratitude as a booster shot for $\begin{array}{lllll}\text { romantic relationships. } & \text { Personal }\end{array}$ http://dx.doi.org/10.1111/j.1475-6811.2010.01273.x

Amis, J. M., \& Cornwell, T. B. (2005). Global sport sponsorship. Oxford: Berg Publishers.

Bartlett, C. A., \& Ghoshal, S. (1989). Managing across borders: The transnational solution. Boston, MA: Harvard Business School Press.

Behling, O., \& Law, K. S. (2000). Translating questionnaires and other research instruments: Problems and solutions. Thousand Oaks, CA: Sage.

Biscaia, R., Correia, A. F., Rosado, A. F., Ross, S. D., \& Maroco, J. (2013). Sport sponsorship: The relationship between team loyalty, sponsorship awareness, attitude toward the sponsor and purchase intentions. Journal of Sport Management, 27(4), 288-302.

Biscaia, R., Correia, A. F., Ross, S. D., \& Rosado, A. F. (2014). Sponsorship effectiveness in professional sport: An examination of recall and recognition among soccer fans. International Journal of Sports Marketing \& Sponsorship, 16(1), 7-23. http://dx.doi.org/10.1108/IJSMS-16-01-2014-B002 
Booton, J. (2013, April 1). Booze and baseball: Slow ticket sales a sign of sluggish growth? Fox Business. Retrieved from http://www.foxbusiness.com/economy/2013/04/01/booze-food-and-baseball-economic-indicators-point-to-s luggish-growth/

Byrne, B. M. (2010). Structural equation modeling with AMOS: Basic concepts, applications, and programming. New York: Routledge.

Chen, F., Curran, P. J., Bollen, K. A., Kirby, J., \& Paxton, P. (2008). An empirical evaluation of the use of fixed cutoff points in RMSEA test statistic in structural equation models. Sociological Methods \& Research, 36(4), 462-494. http://dx.doi.org/10.1177/0049124108314720

Cheung, G. W., \& Rensvold, R. B. (2002). Evaluating goodness-of-fit indexes for testing measurement invariance. Structural Equation Modeling, 9(2), 233-255. http://dx.doi.org/10.1207/S15328007SEM0902_5

Choi, J., Tsuji, Y., Hutchinson, M., \& Bouchet, A. (2011). An investigation of sponsorship implications within a state sports festival: The case of the Florida Sunshine State Games. International Journal of Sports Marketing \& Sponsorship, 12(2), 108-123. http://dx.doi.org/10.1108/IJSMS-12-02-2011-B003

Clarke III, I. (2001). Extreme response style in cross-cultural research. International Marketing Review, 18(3), 301-324. http://dx.doi.org/10.1108/02651330110396488

Close, A. G., \& Lacey, R. (2013). Fit matters? Asymmetrical impact for effectiveness on sponsors and event marketers. Sport Marketing Quarterly, 22(2), 71-82.

De Beuckelaer, A. (2005). Measurement invariance issues in international management research (Unpublished doctoral dissertation). Hasselt University, Diepenbeek, Belgium.

De Mooij, M., \& Hofstede, G. (2010). The Hofstede model: Applications to global branding and advertising strategy and research. International Journal of Advertising, 29(1), 85-110. http://dx.doi.org/10.2501/S026504870920104X

De Mooij, M., \& Hofstede, G. (2011). Cross-cultural consumer behavior: A review of research findings. Journal of International Consumer Marketing, 23(3/4), 181-192.

Doney, P. M., Cannon, J. P., \& Mullen, M. R. (1998). Understanding the influence of national culture on the development of trust. Academy of Management Review, 23(3), 601-620.

Fishbein, M. \& Ajzen, I. (1975). Belief, attitude, intention, and behavior: An introduction to theory and research. Reading, MA: Addison-Wesley.

Fornell, C., \& Larcker, D. F. (1981). Evaluating structural equation models with unobservable variables and measurement error. Journal of Marketing Research, 18(1), 39-50. http://dx.doi.org/10.2307/3151312

Foscht, T., Maloles III, C., Swoboda, B., Morschett, D., \& Sinha, I. (2008). The impact of culture on brand perceptions: A six-nation study. Journal of Product \& Brand Management, 17(3), 131-142. http://dx.doi.org/10.1108/10610420810875052

Grobart, S. (2013, March 28). How Samsung became the world's no. 1 smartphone maker. Business Week. Retrieved

from http://www.businessweek.com/articles/2013-03-28/how-samsung-became-the-worlds-no-dot-1-smartphonemaker

Gwinner, K. (2005). Image transfer in global sport sponsorship: Theoretical support and boundary conditions. In J. M. Amis \& T. B. Cornwell (Eds.), Global sport sponsorship (pp. 163-178). Oxford: Berg Publishers.

Gwinner, K., \& Bennett, G. (2008). The impact of brand cohesiveness and sport identification on brand fit in a sponsorship context. Journal of Sport Management, 22, 410-426.

Gwinner, K., \& Swanson, S. R. (2003). A model of fan identification: Antecedents and sponsorship outcomes. Journal of Services Marketing, 17(3), 275-294. http://dx.doi.org/10.1108/08876040310474828

Hair, J. F., Jr., Black, W. C., Babin, B. J., \& Anderson, R. E. (2009). Multivariate data analysis. Upper Saddle River, NJ: Prentice Hall.

Harzing, A. W., Reiche, B. S., \& Pudelko, M. (2013). Challenges in international survey research: A review with illustrations and suggested solutions for best practice. European Journal of International Management, 7(1), 112-134. http://dx.doi.org/10.1504/EJIM.2013.052090

Hofstede, G., Hofstede, G. J., \& Minkov, M. (2010). Cultures and organizations, software of the mind: 
Intercultural cooperation and its importance for survival. New York: McGraw-Hill Companies, Inc.

Hu, L., \& Bentler, P. M. (1999). Cutoff criteria for fit indexes in covariance structure analysis: Coventional criteria versus new alternatives. Structural Equation Modeling, 6(1), 1-55. http://dx.doi.org/10.1080/10705519909540118

Huff, L., \& Kelley, L. (2005). Is collectivism a liability? The impact of culture on organizational trust and customer orientation: A seven-nation study. Journal of Business Research, 58(1), 96-102. http://dx.doi.org/10.1016/S0148-2963(02)00478-2

Jensen, R. W., Bowman, N. D., Wang, Y., \& Larson, B. V. (2012). New league, new market and new sponsorship: An exploratory study of attitudes towards shirt sponsorship in Major League Soccer. Soccer \& Society, 13(4), 536-554. http://dx.doi.org/10.1080/14660970.2012.677227

Keller, K. L. (1993). Conceptualizing, measuring, and managing customer-based brand equity. Journal of Marketing, 57(1), 1-22. http://dx.doi.org/10.2307/1252054

Kim, Y. K., Smith, R., \& James, J. D. (2010). The role of gratitude in sponsorship: The case of participant sports. International Journal of Sports Marketing \& Sponsorship, 12(1), 53-75. http://dx.doi.org/10.1108/IJSMS-12-01-2010-B006

Ko, Y. J., Kim, K. T., Claussen, C. L., \& Kim, T. H. (2008). The effects of sport involvement, sponsor awareness and corporate image on intention to purchase sponsors' products. International Journal of Sports Marketing \& Sponsorship, 9(2), 79-94. http://dx.doi.org/10.1108/IJSMS-09-02-2008-B004

Lukas, P. (2009, June 2). Is this the slippery slope of uniforms? ESPN. Retrieved from http://sports.espn.go.com/espn/page2/story?page=lukas/090602\&amp;sportCat=wnba

Maxwell, H., \& Lough, N. (2009). Signage vs. no signage: An analysis of sponsorship recognition in women's college basketball. Sport Marketing Quarterly, 18, 188-198.

Olson, E. L., \& Thjømøe, H. M. (2011). Explaining and articulating the fit construct in sponsorship. Journal of Advertising, 40(1), 57-70. http://dx.doi.org/10.2753/JOA0091-3367400104

Palmatier, R. W., Jarvis, C. B., Bechkoff, J. R., \& Kardes, F. R. (2009). The role of customer gratitude in relationship marketing. Journal of Marketing, 73(5), 1-18. http://dx.doi.org/10.1509/jmkg.73.5.1

Poon, D. T. Y., \& Prendergast, G. (2006). A new framework for evaluating sponsorship opportunities. International Journal of Advertising, 25(4), 471-488.

Pyun, D. Y., Kwon, H. H., \& Lee, C. W. (2011). The influences of perceived brand quality and ethnocentrism on consumption patterns of a global sports brand: The case of Korean college students. International Journal of Sports Marketing \& Sponsorship, 13(1), 23-37. http://dx.doi.org/10.1108/IJSMS-13-01-2011-B003

Rines, S. (2002). Guinness Rugby World Cup sponsorship: A global platform for meeting business objectives. International Journal of Sports Marketing \& Sponsorship, 3(4), 449-465. http://dx.doi.org/10.1108/IJSMS-03-04-2002-B007

Santomier, J. P. (2008). New media, branding and global sports sponsorship. International Journal of Sports Marketing \& Sponsorship, 10(1), 15-28. http://dx.doi.org/10.1108/IJSMS-10-01-2008-B005

Schumacker, R. E., \& Lomax, R. G. (2010). A beginner's guide to structural equation modeling. New York, NY: Routledge.

Schumann, J. H., Wangenheim, F., Stringfellow, A., Yang, Z., Blazevic, V., Praxmarer, S., ... \& Jiménez, F. R. (2010). Cross-cultural differences in the effect of received word-of-mouth referral in relational service exchange. Journal of International Marketing, 18(3), 62-80. http://dx.doi.org/10.1509/jimk.18.3.62

Söderman, S., \& Dolles, H. (2013). Handbook of research on sport and business. Cheltenham, UK: Edward Elgar Publishing. http://dx.doi.org/10.4337/9781781005866

Spears, N., \& Singh, S. N. (2004). Measuring attitude toward the brand and purchase intentions. Journal of Current Issues \& Research in Advertising, 26(2), 53-66. http://dx.doi.org/10.1080/10641734.2004.10505164

Sun, B., \& Morwitz, V. G. (2010). Stated intentions and purchase behavior: A unified model. International Journal of Research in Marketing, 27(4), 356-366. http://dx.doi.org/10.1016/j.ijresmar.2010.06.001

Sutton, W. A., McDonald, M., \& Milne, G. R. (1997). Creating and fostering fan identification in professional sports. Sport Marketing Quarterly, 6(1), 15-22. 
Van Slyke, C., Lou, H., \& Belanger, F. (2001). Cultural differences in perceptions of electronic commerce: A comparison of three countries. Proceedings of the Decision Science Institute, 4(1), 1-13.

Walsh, P., Kim, Y. J., \& Ross, S. D. (2008). Brand recall and recognition: A comparison of television and sport video games as presentation modes. Sport Marketing Quarterly, 17(4), 201-208.

Wann, D. L., \& Branscombe, N. R. (1995). Influence of level of identification with a group and physiological arousal on perceived intergroup complexity. British Journal of Social Psychology, 34(3), 223-235. http://dx.doi.org/10.1111/j.2044-8309.1995.tb01060.x

Woodside, F. M., \& Summers, J. (2012). The impact of sponsorship awareness in low involvement settings. Contemporary Management Research, 8(3), 205-228. http://dx.doi.org/10.7903/cmr.11154

\section{Copyrights}

Copyright for this article is retained by the author(s), with first publication rights granted to the journal.

This is an open-access article distributed under the terms and conditions of the Creative Commons Attribution license (http://creativecommons.org/licenses/by/3.0/). 